\title{
O ORIENTE MÉDIO NA AGENDA BRASILEIRA DE COOPERAÇÃO SUL-SUL (2000-2020)
}

\author{
The Middle East In The Brazilian Agenda For South-South Cooperation \\ (2000-2020)
}

DOI: 10.5380/cg.v9i2.72917

Issam Rabih Menem

\begin{abstract}
Resumo
Este artigo tem como propósito identificar o Oriente Médio na agenda brasileira (2000-2020) de Cooperação Sul-Sul, ferramenta demasiadamente explorada pela diplomacia brasileira como fonte de poder brando. Os países do Oriente Médio representam um importante destino dos produtos da agropecuária brasileira, setor estratégico de economias exportadoras de produtos primários. Como método de análise, explorou-se o repositório da Agência Brasileira de Cooperação, o acervo do Ministério das Relações Exteriores e artigos acadêmicos. A relação, que até então era apenas migratória e cultural, ganha uma notoriedade política e econômica a partir da década de 1970. O Brasil aproximou-se de forma inédita e estratégica de países árabes, como o Iraque, Arábia Saudita e Líbia, para resguardar-se de uma importante vulnerabilidade energética. Porém, por diferentes variáveis, a relação deteriorou-se a partir da metade dos anos de 1980. O trabalho sustenta que a ascensão do presidente Lula da Silva foi primordial para a introdução do Oriente Médio na agenda brasileira de Cooperação Sul-Sul. A aproximação com o Oriente Médio ressurge na década de 2000 com o protagonismo do presidente Lula na criação da Cúpula América do Sul - Países Árabes (ASPA) e no fortalecimento da Agência Brasileira de Cooperação. Todavia, percebeu-se que as relações políticas e econômicas com Oriente Médio voltam a perder intensidade ainda no primeiro governo da presidente Dilma Rousseff, devido a uma profunda crise política e econômica que assolou o Brasil. Desde então, o Oriente Médio perde protagonismo na Política Externa Brasileira, principalmente no que tange à Cooperação Sul-Sul.
\end{abstract}

Palavras-Chave: Brasil; Oriente Médio; Cooperação Sul-Sul.

\begin{abstract}
This article aims to identify the Middle East in the Brazilian agenda (2000-2020) of South-South Cooperation, a tool that is overexploited by Brazilian diplomacy as a source of soft power. The countries of the Middle East represent an important destination for Brazilian agricultural products, a strategic sector of economies that export primary products. As a method of analysis, the Brazilian Cooperation Agency repository, the collection of the Ministry of Foreign Affairs and academic articles were explored. The relationship that, until then, was only migratory and cultural, has gained political and economic notoriety since the 1970s. Brazil has approached, in an unprecedented and strategic way, Arab countries such as Iraq, Saudi Arabia and Libya to protect itself from an important energy vulnerability. However, due to different variables, the relationship deteriorated from the mid-1980s. The work concludes that the rise of President Lula da Silva was essential for the introduction of the Middle East in the Brazilian agenda of South-South Cooperation. The rapprochement with the Middle East reappears in the 200os with the role of President Lula in the creation of the South America - Arab Countries Summit (ASPA) and in the strengthening of the Brazilian Cooperation Agency. However, it was noticed that political and economic relations with the Middle East are losing their intensity even in the first government of President Dilma Rousseff, due to a deep political and economic crisis that devastated Brazil. Since then, the Middle East has lost prominence in Brazilian Foreign Policy, especially with regard to South-South Cooperation.
\end{abstract}

Keywords: Brazil; Middle East; South-South Cooperation.

${ }^{1}$ Doutorando pelo Programa de Pós-Graduação em Estudos Estratégicos Internacionais da Universidade Federal do Rio Grande do Sul (UFRGS) e Mestre em Integração Contemporânea da América Latina pela Universidade Federal da Integração Latino-Americana (UNILA). E-mail: issam_menem@hotmail.com. ORCID: https://orcid.org/o000-0002-4636-8666. 


\section{INTRODUÇÃO}

O presente artigo tem como objetivo identificar como o Oriente Médio, região de grande interesse da agropecuária brasileira, integrou a agenda de cooperação Sul-Sul brasileira a partir dos anos 2000. O trabalho se inicia apresentando aspectos históricos dessa relação como a imigração árabe para o Brasil e suas influências culturais e políticas. Posteriormente, como método de análise, são elaborados quadros detalhando ações desenvolvidas pela Agência Brasileira de Cooperação (ABC) com países árabes, tendo como base projetos de Cooperação Sul-Sul; ações humanitárias e iniciativas políticas e econômicas desenvolvidas e fomentadas nas últimas duas décadas (20002020). Por fim, é realizada uma breve análise do perigo que o governo de Jair Bolsonaro representa para a histórica e estratégica relação do Brasil com o Oriente Médio.

$\mathrm{O}$ primeiro contato entre sul-americanos e árabes antecedeu o importante processo imigratório dos árabes à região no final do século XIX. A colonização, principalmente a portuguesa, foi responsável pelo primeiro elo entre árabes e América do Sul. Este contato ocorreu indiretamente de diversas formas: pela língua, arquitetura, culinária, técnicas de agricultura, assim como na medicina.

A grave crise socioeconômica resultante da decadência do Império Otomano no início do século XX foi a principal variável que acarretou uma grande imigração da região do Oriente Médio, principalmente de libaneses, sírios e palestinos para a América do Sul. As visitas de Dom Pedro II à Palestina, Líbano, Síria e Egito nos anos de 1871 e 1877, foi outro elemento importante que influenciou a escolha do destino da imigração dos árabes. A viagem do imperador foi estratégica, com o objetivo de incentivar a ocupação e a povoação do território brasileiro mostrando as vantagens e oportunidades que sua terra oferecia. A partir dos anos de 1900, de forma progressiva, os árabes se juntaram ao conglomerado de imigrantes italianos, alemães, japoneses, espanhóis, entre outros, em território tupiniquim (ICARABE, 2017).

O perfil liberal destes imigrantes e uma impressionante capacidade de adaptação favoreceram uma inserção bem-sucedida deste povo nas respectivas sociedades, em diferentes camadas sociais, seja nos grandes centros ou nas regiões interioranas. Os árabes prosperaram não só no comércio, mas também na vida política de suas comunidades, os exemplos são muitos, desde lideranças comunitárias até presidências de governos, como Carlos Menem na Argentina, Julio Turbay na Colômbia, Bucaran no Equador e Michel Temer no Brasil (TRUZZI, 2007, p. 360-364).

Em entrevista realizada ao autor do artigo, o embaixador da Liga dos Estados Árabes, Qais Marouf Kheiro Shqair, destaca o histórico de bom relacionamento entre o mundo árabe e o Brasil:

O Brasil é um país muito querido para nós do mundo árabe e islâmico. Historicamente, o posicionamento de sua Política Externa sempre foi cordial ao mundo árabe e principalmente em relação ao conflito Palestino, inclusive reconhecendo o Estado da Palestina no ano de 2010. Nosso relacionamento com o Brasil é um relacionamento com um país amigo (SHQAIR, 2019). 
Apesar da relação histórica e cultural dos imigrantes árabes, até os anos de 1970, o Brasil pouco se manifestava ou empenhava-se de modo apropriado sobre temas relacionados ao Oriente Médio (salvo a participação do brasileiro Osvaldo Aranha presidindo a Assembleia Geral da ONU no episódio da criação do Estado de Israel), ou temas que transcendiam a América Latina (AMORIM, 2015, p. 106).

Este cenário se modifica com o importante episódio da Crise do Petróleo de 1973, quando, estrategicamente, o Brasil amplia suas relações diplomáticas e comerciais com o mundo árabe, estimulado pela grande dependência do país em relação ao petróleo árabe, uma solução imediata para a demanda energética brasileira (AMORIM, 2015, p. 107).

O país sul-americano vivia um momento sem igual de sua economia conhecido por "Milagre Econômico": o Produto Interno Bruto brasileiro crescia por volta de 10\% entre 1968 e 1974. Entretanto, cerca de $80 \%$ do petróleo que subsidiava a indústria brasileira era importado, principalmente do Oriente Médio.

A aproximação com os árabes era crucial para proteger a vulnerabilidade e a sensibilidade da economia brasileira. Foi na primeira grande crise do petróleo (1973) que os governantes brasileiros deram atenção especial para a região. Posteriormente, os países árabes deixam de ser apenas vendedores de petróleo e passam a ser os grandes clientes da indústria brasileira como forma de pagamento do óleo árabe. Arábia Saudita e Iraque, por exemplo, representaram, entre 1976 e 1984, dois dos três maiores importadores de produtos brasileiros (BRUN, 2012, p. 73-74).

O relacionamento com os iraquianos merece um devido destaque. O Iraque se caracteriza por ser um dos mais importantes parceiros internacionais que o Brasil já teve em sua história. A experiência com o país árabe nas décadas de 1970 e 1980 destacou-se principalmente pelo intercâmbio de know-how técnico; de produtos industrializados, armas e blindados; exploração de petróleo, até parcerias em áreas polêmicas, como na de cooperação nuclear (PREISS, 2015, p. 64).

Passada a Guerra de Yom Kippur (1973) e o primeiro choque do petróleo (1973), os grandes produtores de petróleo, como o Iraque, passaram a faturar mais que o habitual. Saddam Hussein voltou este capital para a modernização da infraestrutura do país e o fortalecimento do exército nacional. Entre os projetos de infraestrutura, destacaram-se a construção de estradas, ferrovias, projetos de irrigação, eletrificação e implantação de fábricas. É neste momento que surgem sedutoras oportunidades tanto para o governo brasileiro, que visava solucionar sua crise energética e, ao mesmo tempo, elevar o status do Brasil no sistema internacional, como para as empresas brasileiras (MENEM, 2019, p. 50).

Entre as empresas brasileiras que atuaram no Iraque, destaca-se a empreiteira Mendes Junior, que naquele momento, era uma extensão da Política Externa brasileira no mundo. Os projetos desenvolvidos em território iraquiano fizeram com que a Mendes Junior se apresentasse como uma das " 15 maiores multinacionais de engenharia do globo entre 1979 e 1982, chegando à $13^{\mathrm{a}}$ 
posição em 1980, tendo 50\% de seu faturamento oriundo de obras realizadas fora do país" (CAMPOS, 2017, p. 9). Infelizmente, nem todos os projetos puderam ser concluídos, em decorrência de embargos econômicos ao Iraque, mas principalmente, pela invasão do Kuwait. Dentre os projetos de maior expressão estão: Ferrovia Bagdá -Al Qaim- Akshat; Rodovia Expressway; Ferrovia De Heet e Projeto Sifão (estação de bombeamento de água do rio Eufrates) (CAMPOS, 2017, p. 9).

O relacionamento do Brasil com os árabes se deteriora na década de 1980, quando a economia brasileira encarou uma grave crise de dívida, que alcançou cerca de 40\% de seu PIB, provocando uma suspensão dos pagamentos de contratos internacionais. Este episódio refletiu negativamente nos laços internacionais que o país vinha construindo nas últimas décadas e, junto a outros fatores políticos, o Brasil perdeu o status que tinha junto aos árabes tanto como parceiro econômico quanto político (BRUN, 2012, p. 77).

Esquecido, o Oriente Médio voltou com força ao radar de interesses da política externa brasileira na virada do milênio, norteada por um novo modelo de inserção internacional. Foi no governo do presidente Luiz Inácio Lula da Silva (2003-2011) que se observou uma reaproximação política entre as duas regiões. Neste governo, como visto, delinearam-se diretrizes de: expandir a atuação diplomática por todos os continentes, buscar novos parceiros e formas de cooperação em diferentes áreas, reduzindo sua vulnerabilidade em relação ao exterior e aumentar sua influência política no cenário internacional (SILVA; KUNRATH, 2010, p. 19).

Entretanto, é nítida a falta de uma grande estratégia brasileira para o Oriente Médio. Ao longo dos últimos anos, o Brasil mostrou um padrão muitas vezes dúbio, contraditório e incoerente dos seus princípios lógicos frente aos numerosos conflitos e litígios no mundo árabe. A ausência de uma grande estratégia condena Estados a desenvolverem políticas ineficientes e contraditórias diante dos desafios internacionais (KALOUT \& DEGAUT, 2017, p. 18).

\section{O ESPÍRITO DE BANDUNG: COOPERAÇÃo SUL-SUL ENTRE OS PAÍSES NÃO ALINHADOS}

O termo "Terceiro Mundo" surge por volta de 1950 e logo se populariza, tornando-se sinônimo de um grupo de países "subdesenvolvidos", este grupo, em grande parte, compartilha alguns traços, como: pobreza; subdesenvolvimento; ex-colônias; população não branca; economia desarticulada; fraco capital produtivo; predomínio da agricultura; instrução de nível deficiente, etc. (WOLKMER, 1989, p. 12).

As economias deste grupo de países são economias de dependência, pois são reguladas e controladas pelo interesse do capital central dominante. De modo geral, os países terceiro-mundistas atuam no mercado internacional como meros exportadores de matéria-prima e importadores de tecnologia e capital. Assim, os países "desenvolvidos” praticam uma dominância econômica que 
aparece sob forma de uma moeda-padrão rodeada de organizações financeiras, como o Fundo Monetário Internacional e o Banco Mundial (WOLKMER, 1989, p. 20).

Dado este cenário, pós-Segunda Guerra Mundial, surge o Movimento dos Países Não Alinhados. Países periféricos do sistema, então conhecidos como terceiro-mundistas, reuniram-se na cidade de Bandung, na Indonésia, no ano de 1955, para criar uma “terceira posição" em relação à posição estadunidense e à posição soviética (BRENER, 1987, p. 79).

Em um mundo bipolar, o sistema internacional é determinado pela qualidade da relação entre as duas grandes potências. Neste cenário, as potências médias e países "subdesenvolvidos” têm à sua frente duas opções: alinhar-se a uma das duas potências ou optar por manter-se neutro e distante do conflito. O grupo que opta por não se alinhar tem a perspectiva de exercer um papel mais ativo na pauta internacional e na mediação em situação de hostilidade (LEITE, 2011, p. 43).

A Conferência de Bandung caracterizou-se como um marco histórico para as Relações SulSul pelo combate à dominação colonial e aos laços de dependência. O maior fruto da conferência foi uma declaração de dez pontos, a saber:

1. Respeito aos direitos fundamentais;

2. Respeito à soberania e integridade territorial de todas as nações;

3. Reconhecimento da igualdade de todas as raças e nações, grandes e pequenas;

4. Não intervenção e não ingerência nos assuntos internos de outro país (autodeterminação dos povos);

5. Respeito pelo direito de cada nação defender-se, individual e coletivamente;

6. Recusa na participação dos preparativos da defesa coletiva destinada a servir aos interesses particulares das superpotências;

7. Abstenção de todo ato ou ameaça de agressão, ou do emprego da força, contra a integridade territorial ou a independência política de outro país;

8. Solução de todos os conflitos internacionais por meios pacíficos (negociações e conciliações, arbitradas por tribunais internacionais);

9. Estímulo aos interesses mútuos de cooperação;

10. Respeito pela justiça e obrigações internacionais (ÍNDIA, 2012).

Na Segunda Conferência, no ano de 1964, no Cairo, o número de participantes duplica. Neste momento, pode-se destacar três grandes líderes à frente do movimento: Nasser, Tito e Nehru (BRENER, 1987, p. 79). Jovens países africanos e asiáticos passavam por um momento de formação de identidade nacional e da manutenção de suas soberanias em meio à Guerra Fria. A partir da criação deste novo "fórum de discussão", estes novos atores trataram entre si de problemas que lhes diziam respeito no sistema internacional (KOCHER, 2004, p. 2). Sobre o resultado do movimento, Brener destaca: "Embora a importância do seu simbolismo no campo diplomático, o movimento não 
conseguiu articular medidas concretas e efetivas. A heterogeneidade política do grupo mostrou ser uma barreira importante para o progresso do movimento" (1987, p. 80).

Este período é marcado pelo início da instrumentalização das relações Sul-Sul e de cooperação técnica no âmbito das Nações Unidas (PEREIRA, MEDEIROS, 2015, p. 130). Provido da resolução 58/220, o comitê de Cooperação Sul-Sul solicita a intensificação da cooperação entre os países em desenvolvimento com o objetivo de fortalecer as diferentes formas de cooperação internacional para o desenvolvimento, sendo elas Sul-Sul, Norte-Sul, multilateral e triangular (CEPAL, 2020).

Assim sendo, o Brasil, um dos protagonistas do "Terceiro Mundo", desenvolve na década de 1980, uma das mais importantes instituições promovedoras e fomentadores de projetos de natureza horizontal "Sul-Sul" entre países em desenvolvimento. Seguindo o método de análise proposto neste artigo, se apresentará em seguida a Agência Brasileira de Cooperação (ABC) e se detalharão projetos brasileiros promovidos junto a região do Oriente Médio.

\subsection{AGÊNCIA BRASILEIRA DE COOPERAÇÃO (ABC)}

Criada há pouco mais de 30 anos (1987), resultante da fusão da Divisão de Cooperação Técnica do Itamaraty e a Subsecretaria de Cooperação Econômica e Técnica Internacional (SUBIN), a Agência Brasileira de Cooperação (ABC), tem como objetivo coordenar, negociar e avaliar programas e ações de cooperação técnica e humanitária internacionais do Brasil em dois segmentos: multilateral e bilateral, na vertente Brasil-exterior e exterior-Brasil. Norteada pelo princípio da "cooperação entre povos para o progresso da humanidade", a agência desenvolveu nestas três décadas mais de sete mil projetos em 108 países da América Latina, Ásia, África, Oceania e Europa. Destaca-se neste processo, a participação de mais de 120 empresas brasileiras de diferentes ramos (ABC, 2019).

Após explorar o repositório de projetos da Agência ABC, disponibilizado em seu sítio eletrônico, desenvolveu-se um quadro com todas as ações que o governo brasileiro promoveu junto a países da região do Oriente Médio, desde a sua criação.

QUADRO I - PRINCIPAIS PROJETOS DE COOPERAÇÃO ENTRE BRASIL E O LEVANTE ÁRABE+EGITO

\begin{tabular}{|c|c|c|}
\hline PAÍS & PROJETOS / MISSÕES & TIPO DE COOPERAÇÃO \\
\hline \multirow{4}{*}{ EGITO } & $\begin{array}{l}\text { Missão de Prospecção para Desenvolvimento de Projeto de } \\
\text { Cooperaçãa Técnica na Área de Semiárido e Recursos Hídricos } \\
\text { entre o Brasil e Países Árabes (2007) }\end{array}$ & \multirow{2}{*}{ Cooperação Sul-Sul } \\
\hline & $\begin{array}{l}\text { Visita técnica de representantes dos Ministérios do Meio Ambiente } \\
\text { do Egito para intercâmbio de conhecimentos na área de } \\
\text { preservação ambiental (2007) }\end{array}$ & \\
\hline & $\begin{array}{l}\text { II Semana do Etanol - Compartilhando a Experiência Brasileira } \\
\text { (2009) }\end{array}$ & \multirow[t]{2}{*}{ Cooperação Trilateral } \\
\hline & $\begin{array}{l}\text { Missão Diagnóstica de Técnicos do Governo Brasileiro nas Áreas } \\
\text { de Agricultura e Saúde do Egito (2010) }\end{array}$ & \\
\hline
\end{tabular}


QUADRO I - PRINCIPAIS PROJETOS DE COOPERAÇÃO ENTRE BRASIL E O LEVANTE ÁRABE+EGITO

\begin{tabular}{|c|c|c|}
\hline$P A \mathscr{I} S$ & PROJETOS / MISSÕES & TIPO DE COOPERAÇÃO \\
\hline EGITO & $\begin{array}{l}\text { Treinamento internacional em tecnologias de convivência em } \\
\text { regiões áridas e semiáridas (2011) }\end{array}$ & Cooperação Sul-Sul \\
\hline IRAQUE & $\begin{array}{l}\text { Treinamento internacional em tecnologias de convivência em } \\
\text { regiões áridas e semiáridas (2011) }\end{array}$ & Cooperação Sul-Sul \\
\hline \multirow{8}{*}{ LÍBANO } & $\begin{array}{l}\text { Missão de Prospecção para Identificação de possibilidades de } \\
\text { Cooperação Técnica para Apoiar os Esforços de Reconstrução do } \\
\text { Líbano (2006) }\end{array}$ & \multirow{8}{*}{ Cooperação Sul-Sul } \\
\hline & $\begin{array}{l}\text { Missão de Prospecção para Identificação de Possibilidades de } \\
\text { Cooperação Técnica na Área da Agricultura (2006) }\end{array}$ & \\
\hline & $\begin{array}{l}\text { Missão de Prospecção para Identificação de Possibilidade de } \\
\text { Cooperação Técnica na Área da Saúde no Líbano (2006) }\end{array}$ & \\
\hline & $\begin{array}{l}\text { Capacitação de técnicos Libaneses em Atividades Agropecuárias } \\
\text { (2006) }\end{array}$ & \\
\hline & $\begin{array}{l}\text { Capacitação Técnica para resposta rápida no controle de surtos e } \\
\text { epidemias (2007) }\end{array}$ & \\
\hline & Revisão do Protocolo de Patologias (2007) & \\
\hline & Missão Prospectiva na Área de Medicamentos Genéricos (2009) & \\
\hline & $\begin{array}{l}\text { Treinamento internacional em tecnologias de convivência em } \\
\text { regiões áridas e semiáridas (2011) }\end{array}$ & \\
\hline \multirow{7}{*}{ PALESTINA } & Apoio ao Centro Palestino de Mídia (2009) & \multirow{7}{*}{ Cooperação Sul-Sul } \\
\hline & $\begin{array}{l}\text { Treinamento de técnicos palestinos na área de Desenvolvimento } \\
\text { Urbano (2009) }\end{array}$ & \\
\hline & $\begin{array}{l}\text { Capacitação em Técnicas de Fisioterapia para Profissionais da } \\
\text { Saúde Palestinos (2010) }\end{array}$ & \\
\hline & Capacitação para Diplomatas da Palestina (2010) & \\
\hline & $\begin{array}{l}\text { Missão Cooperação Técnica em Saúde, Saneamento e Gestão de } \\
\text { Fundos Públicos na Palestina (2010) }\end{array}$ & \\
\hline & $\begin{array}{l}\text { Capacitação em Técnicas de Fisioterapia para Profissionais da } \\
\text { Saúde Palestinos - II Edição do Workshop de Fisioterapia em } \\
\text { Ramallah (2010) }\end{array}$ & \\
\hline & $\begin{array}{l}\text { Capacitação técnica em Gestão de Resíduos Sólidos e Gestão de } \\
\text { Fundos de Financiamento Público na Palestina (2011) }\end{array}$ & \\
\hline \multirow[b]{2}{*}{ SÍRIA } & Capacitação Técnica Em Transplante De Fígado (2011) & \multirow[b]{2}{*}{ Cooperação Sul-Sul } \\
\hline & $\begin{array}{l}\text { Treinamento internacional em tecnologias de convivência em } \\
\text { regiões áridas e semiáridas (2011) }\end{array}$ & \\
\hline
\end{tabular}

Fonte: Quadro desenvolvido pelo autor com base no acervo digital da Agência Brasileira de Cooperação. (ABC, 2019).

É inquestionável que grande parte dos projetos da Agência (ABC) foram e ainda são desenvolvidos junto a países latino-americanos e africanos. Porém, é pertinente realçar os "poucos” projetos com a região do Oriente Médio. Dentre os projetos expostos no Quadro I, a maioria são desenvolvidos junto a países de economias pequenas e irrelevantes para o comércio exterior brasileiro, exceto o Egito.

No quadro anterior (1), pode-se enfatizar os projetos desenvolvidos junto à República do Líbano logo após o conflito com Israel (2006), quando o país árabe sofreu importantes ataques à sua infraestrutura afetando todos os setores de sua sociedade. Não distante, a Palestina vive um cenário contínuo de conflitos militares, por consequência, tem grande parte de sua infraestrutura básica destruída e a qualidade de vida de seus cidadãos afetada. O país recebeu importantes projetos relacionados à área da saúde, desenvolvimento urbano e administração pública. 
A seguir, serão expostos algumas das iniciativas da Coordenação-Geral de Cooperação Humanitária, um organismo da Agência Brasileira de Cooperação. A política de solidariedade da diplomacia brasileira integra uma estratégia de longo prazo de interesse nacional. A longo prazo, o exercício de solidariedade retorna ao país em forma de prestígio ao país "doador" (NASSER, 2012, p. 234).

\subsection{COORDENAÇÃO-GERAL DE COOPERAÇÃO HUMANITÁRIA (CGCH)}

Criada no ano de 2017, a Coordenação-Geral de Cooperação Humanitária (CGCH), da Agência Brasileira de Cooperação ( $\mathrm{ABC}$ ), tem como principais responsabilidades: a coordenação de ações emergenciais de caráter humanitário, desde doação de alimentos e medicamentos até acompanhar iniciativas de cooperação em temas humanitários junto a atores governamentais e não governamentais (ABC, 2019).

Neste contexto, destaca-se o artigo 11 da Lei ${ }^{0}$ 13.684, que estabelece:

A União poderá prestar cooperação humanitária, sob a coordenação do Ministério das Relações Exteriores, a fim de apoiar países ou populações que se encontrem em estado de conflito armado, de desastre natural, de calamidade pública, de insegurança alimentar e nutricional ou em outra situação de emergência ou de vulnerabilidade, inclusive grave ameaça à vida, à saúde e aos direitos humanos ou humanitários de sua população (BRASIL, 2018).

A esmagadora maioria das ações promovidas pela CGCH são no continente americano, mais precisamente na América Latina, porém, quando se analisa o relatório dos três anos de funcionamento da coordenação, a CGCH registra doações para três países árabes: Líbano, Palestina e Síria (Quadro II).

QUADRO II - AÇÕES DA CGCH COM PAÍSES ÁRABES

\begin{tabular}{|c|c|c|c|}
\hline$A N O$ & PAÍS & MOTIVO & $A C ̧ \tilde{A} O$ \\
\hline 2016 & Palestina & $\begin{array}{l}\text { Segurança } \\
\text { Alimentar }\end{array}$ & $\begin{array}{l}\text { O governo brasileiro contribuiu à organização das Nações Unidas para } \\
\text { Alimentação e Agricultura (FAO), por meio do escritório da FAO no Brasil, US\$ } \\
200.000 \text {,oo destinados a açôes emergenciais em apoio à produção agrícola } \\
\text { familiar na Faixa de Gaza. }\end{array}$ \\
\hline 2017 & Síria & $\begin{array}{l}\text { Conflito } \\
\text { Armado }\end{array}$ & $\begin{array}{l}\text { Foram doadas } 54.640 \text { unidades de medicamentos necessários às operações de } \\
\text { cooperação humanitária voltada para mitigar os efeitos do conflito. }\end{array}$ \\
\hline 2018 & Líbano & $\begin{array}{l}\text { Fluxo } \\
\text { Migratório }\end{array}$ & $\begin{array}{l}\text { Doação de } 40 \text { mil frascos de insulina humana do tipo NHP e } 4.000 \text { frascos de } \\
\text { insulina humana tipo regular. }\end{array}$ \\
\hline
\end{tabular}

Diferentemente dos Projetos expostos no Quadro 1, as ações da Coordenação-Geral de Cooperação Humanitária são de anos mais recentes. A primeira, no ano de 2016, foi uma contribuição financeira para projetos de produção agrícola familiar na Palestina. Nos dois anos seguintes, o governo brasileiro doou medicamentos para ações médicas na Síria e para abastecer campos de refugiados sírios no Líbano. 


\section{RELAÇÕES AMÉRICA DO SUL - ORIENTE MÉDIO NOS ANOS 2000-2010: ASPA}

América do Sul e Oriente Médio sempre foram regiões muito distantes, geograficamente e politicamente. O Brasil foi o país que assumiu a frente latino-americana a procurar e fomentar um diálogo com os árabes. O grande protagonista da inserção do Oriente Médio na agenda da Política Externa contemporânea, não só do Brasil, mas de outros países sul-americanos, foi a figura do expresidente Lula da Silva, ao realizar uma estratégica turnê por cinco países da região, sendo eles: Síria, Líbano, Emirados Árabes Unidos, Líbia e Egito. O objetivo da turnê era claro: elevar o nível de relacionamento econômico, político e comercial com o mundo árabe. Para isso, o presidente foi acompanhado de uma centena de empresários de diferentes ramos (VAGNI, 2009, p. 3). Foi nesta viagem que a Cúpula América do Sul - Países Árabes (ASPA) começou a tomar forma.

Proposta em 2003 e realizada pela primeira vez em 2005, a Cúpula América do Sul-Países Árabes (ASPA) é considerado um mecanismo de cooperação Sul-Sul e de coordenação política multilateral. Realizada em Brasília, a primeira edição da cúpula destacou-se na mídia internacional como um potencial novo "eixo Sul-Sul”. Jornais como El País e Le Monde utilizaram termos como "histórico" e "inédito" para o encontro. Além de ter sido a primeira viagem oficial de diferentes líderes árabes ao Brasil, foi um dos raros momentos em que se reuniram tantos líderes árabes em um mesmo ambiente. O ex-ministro de Relações Exteriores afirma que a cúpula ASPA representou um grande triunfo da política externa "ativa e altiva" brasileira (AMORIM, 2015, p. 173-174). Integram a cúpula 34 países entre sul-americanos e árabes, são eles:

Sul-Americanos: Argentina, Bolívia, Brasil, Chile, Colômbia, Equador, Guiana, Paraguai, Peru, Suriname, Uruguai e Venezuela.

Árabes: Arábia Saudita, Argélia, Bahrein, Catar, Comores, Djibouti, Egito, Emirados Árabes Unidos, Iêmen, Iraque, Jordânia, Kuwait, Líbano, Líbia, Marrocos, Mauritânia, Omã, Palestina, Síria, Somália, Sudão e Tunísia (ITAMARATY, 2012).

Foram estabelecidos cinco comitês principais para implementar ações de cooperação Sul-Sul, são eles:

- Ciência e Tecnologia (com dois Subcomitês, a saber: Cooperação Agrícola Energia);

- Assuntos Ambientais (com um Subcomitê de Combate à Desertificação);

- Cultura e Educação;

- Economia; e

- Assuntos Sociais (ITAMARATY, 2012).

Temas muito relevantes foram discutidos na quarta edição da cúpula, que foi realizada em Riad, capital da Arábia Saudita. Dentre estes temas, destacaram-se o incremento das possibilidades de cooperação, desenvolvimento, redução da pobreza, inovação e intercâmbio técnico e cultural entre os membros. Além de questões econômicas e sociais, temas políticos foram dialogados, como a ocupação e a excessiva agressão militar israelense ao povo palestino, assim como o conflito armado 
sírio e todas suas consequências negativas, gerando uma situação humanitária crítica e uma das maiores ondas de refugiados desde a última grande guerra (ITAMARATY, 2012).

Dentre estes frutos, deve-se destacar um dos projetos mais consolidados, a BibliASPA, biblioteca e centro de pesquisa para difundir a cultura árabe e muçulmana. Instituição que atualmente se destaca no Brasil por apoiar refugiados recém-chegados com aulas de português, assistência jurídica e psicológica, alimentação, transporte, etc. (BIBLIASPA, 2018).

Apesar de a Cúpula abordar e discutir vários assuntos de cunho social e político, na prática, o comitê de maior sucesso da cúpula foi o econômico, apresentando um aumento considerável no intercâmbio comercial, que aumentou cerca de 140\% de 2005 (primeira edição da Cúpula ASPA) a 2009. Neste intercâmbio, os sul-americanos venderam (e ainda vendem) basicamente carne, leite, soja, milho, trigo e aço, e do outro lado, os árabes restringem-se a exportar petróleo e seus derivados. O cenário político e econômico internacional favoreceu este relacionamento, ressaltando a alta do preço do petróleo, que aumentou o poder de compra dos árabes, as missões comerciais sulamericanas, problemas geopolíticos e o boicote a produtos norte-americanos no Oriente Médio (VAGNI, 2009, p. 5).

Durante o debate sobre possibilidades de cooperação entre árabes e sul-americanos, o embaixador da Liga dos Estados Árabes ressalta com muito entusiasmo a potencialidade da relação do Brasil com o mundo árabe e islâmico:

O Brasil é uma potência, tem uma população que gira em torno de 220 milhões, sexta ou sétima economia do mundo, existem muitas oportunidades que podem se abrir entre ambos. O mundo árabe é formado por 22 países e o mundo islâmico é formado por cerca de 57 países, dentre eles, importantes nações como a Indonésia, Malásia, Turquia e Egito, não queremos que esse relacionamento com o Brasil seja apenas no âmbito comercial, existe muito espaço para desenvolver projetos de cooperação estratégica entre nós (SHQAIR, 2019).

Em seguida, o embaixador revelou uma antiga proposta árabe de desenvolver um projeto ousado que tinha como objetivo integrar logisticamente as indústrias brasileiras e o mercado árabe:

Há algum tempo atrás, durante a visita do presidente da Liga Árabe ao Brasil, foi oferecido um acordo para o Brasil para desenvolver uma obra logística em três ou quatro portos estratégicos podendo ser um em Rabat no Marrocos e outros no Mar Mediterrâneo, como na Argélia e outro em Alexandria para diminuir os custos logísticos dos produtos brasileiros ou até para as grandes empresas brasileiras de frango ou do ramo automobilístico estruturarem plantas industriais nestas cidades integrando logisticamente as duas regiões ou até desenvolverem joint ventures entre empresas brasileiras e árabes (SHQAIR, 2019).

Apesar do interesse em dar continuidade nesta parceria, logo ao assumir a presidência, a expresidente Dilma Rousseff se deparou com o Oriente Médio borbulhando em revoltas. Além do cenário instável do Oriente Médio, batia na porta da América Latina uma grave crise econômica que levou complicações financeiras aos países da região. Internamente, Dilma lidava com manifestações 
populares e a queda de sua popularidade, além de ter a responsabilidade de sediar dois megaeventos esportivos, a Copa do Mundo de futebol masculino de 2014 e os Jogos Olímpicos de 2016, uma vez que tais fenômenos políticos nacionais podem ter provocado maior atenção do governo ao âmbito interno. Esta conjuntura provocou mudanças na política externa, reduzindo a margem de atuação da política externa do Brasil no Oriente Médio e em negociações de ordem multilateral. Estas variáveis internas e externas levaram a política externa brasileira a ser menos proativa não só com o Oriente Médio, mas com o sistema internacional de um modo geral (CORNETET, 2014, p. 136-141).

Em abril de 2019, o governo do brasileiro formaliza a saída da União das Nações SulAmericanas (Unasul) junto a outros governos sul-americanos (Argentina, Chile, Colômbia, Paraguai e Peru) (AGÊNCIA BRASIL, 2019). O descredenciamento da Unasul por parte das maiores economias da região é fator agravante do declínio da integração árabe-sul-americana, já que a Unasul é a instituição representativa dos países sul-americanos perante a Cúpula ASPA.

\section{DESAFIOS}

Passados doze meses do governo de Jair Messias Bolsonaro, a política externa brasileira ainda não demonstra nenhum tipo de política estratégica para o Oriente Médio, mas sim um alinhamento automático aos aliados históricos estadunidenses na região. A recente aproximação do governo de Bolsonaro com os Árabes parece ser estritamente comercial. Desde sua posse em janeiro de 2019, o presidente brasileiro findou o tradicional posicionamento brasileiro neutro e multilateralista frente às crises no Oriente Médio e aplicou um alinhamento incondicional a Israel.

Neste sentido, o embaixador da Liga dos Estados Árabes para o Brasil demonstra um certo pesar em relação a este alinhamento:

O mundo árabe e islâmico não é contra o Brasil fortalecer suas relações com Israel, ao contrário, nós poderemos usufruir deste relacionamento, já que o Brasil é um país amigo dos árabes e, assim, poderá ter um papel importante no debate na operação de paz no Oriente Médio, O Brasil poderia ser o país mediador em que ambos os lados depositam sua confiança durante as negociações (SHQAIR, 2019).

A falta de uma grande estratégia nacional para a região do Oriente Médio, junto à incoerência na conduta da Política Externa brasileira, faz o atual governo contradizer-se repetidas vezes entre o discurso e a ação. Percebe-se que até este momento (01/2020), o alinhamento ideológico automático à política externa estadunidense não rendeu benefícios econômicos concretos para o Brasil (SCHUTTE; DA FONSECA; CARNEIRO, 2019, p. 107).

Em outubro de 2019, em visita à região, Bolsonaro visitou três países, Arábia Saudita, Catar e Emirados Árabes Unidos. Vários acordos foram assinados com estes três países, majoritariamente acordos comerciais relacionados ao agronegócio e à indústria de defesa brasileira, além de uma 
promessa do Fundo Soberano Saudita de investir 10 bilhões de dólares em projetos de infraestrutura no Brasil (DW, 2019).

Por outro lado, o governo brasileiro sediará em fevereiro 2020 uma conferência denominada de "Processo de Varsóvia", um evento com um objetivo claro: conter o Irã. A ação foi lançada pelo presidente norte-americano Donald Trump, oficialmente tem como finalidade debater questões ligadas à crise humanitária e refugiados, porém, empiricamente, é um evento estratégico entre os Estados Unidos e seus aliados externos para debater o Oriente Médio. Os persas condenam a realização da conferência e a consideram "um movimento hostil dos Estados Unidos contra a República Islâmica” (CHADE, 2019). China, Rússia e França recusaram-se a participar da iniciativa (CHADE, 2019).

Ainda no ano de 2019, o Irã ameaçou boicotar produtos agrícolas brasileiros como resposta à "crise dos cargueiros", quando a Petróleo Brasileiro S.A. (Petrobras) se negou a abastecer dois cargueiros iranianos no Porto de Paranaguá (PR), cumprindo sanções unilaterais impostas pelos Estados Unidos ao país persa. Estes fatos permitem perceber a falta de racionalidade da atual política externa brasileira somada à descontinuação do tradicional pragmatismo econômico, sabendo que o Irã é um dos maiores e mais importantes clientes do agronegócio brasileiro (MENEM, 2020, p. 53).

\section{CONSIDERAÇÕES FINAIS}

A relação que até então era apenas migratória e cultural, ganhou uma notoriedade política e econômica a partir da década de 1970. O Brasil aproximou-se de forma inédita e estratégica de países árabes, como o Iraque, Arábia Saudita e Líbia, para resguardar-se de uma importante vulnerabilidade energética. No entanto, por diferentes variáveis geopolíticas e, principalmente, econômicas (Crise da Dívida no Brasil), a relação com os árabes deteriorou-se a partir da metade dos $\operatorname{anos} 1980$.

Como demonstrado no artigo, a ascensão do presidente Lula da Silva (2003) foi primordial para a reaproximação de árabes e brasileiros. A iniciativa mais marcante foi a criação da Cúpula América do Sul - Países Árabes (ASPA) com protagonismo do presidente brasileiro. Este esforço teve importante fruto político e comercial.

O presente artigo identificou que os principais projetos de cooperação Sul-Sul, nas últimas duas décadas, junto a países do Oriente Médio, ocorreram durante os dois governos do presidente Lula (2003-2011), por meio da Agência Brasileira de Cooperação (ABC). Todavia, as relações políticas com os árabes e o Oriente Médio voltam a perder intensidade ainda no primeiro governo da presidente Dilma Rousseff, devido a uma profunda crise política e econômica que assolou o Brasil. Desde então, não se registra nenhum projeto de cooperação relevante junto à região, a não ser doações financeiras por meio de organizações internacionais para ajuda humanitária. 
A partir de 2018, com a posse de Jair Messias Bolsonaro, a relação com o Oriente Médio se deteriora de uma forma nunca vista nos últimos 20 anos (2000-2020). Por questões ideológicas e políticas, o presidente gerou importantes constrangimentos diplomáticos com a Liga Árabe como com o Irã, parceiros estratégicos da economia brasileira. Como constatado até a realização deste trabalho, o Oriente Médio se ausenta de qualquer debate estratégia da política externa brasileira.

*Artigo recebido em 15 de abril de 2020, aprovado em 23 de agosto de 2020.

\section{REFERÊNCIAS}

AGÊNCIA BRASIL. Brasil formaliza saída da Unasul para integrar Prosul. 2019. Disponível $\mathrm{em}:<$ https://agenciabrasil.ebc.com.br/internacional/noticia/2019-04/brasil-formaliza-saida-daunasul-para-integrar-prosul >. Acesso em: 10/12/2020.

AGÊNCIA BRASILEIRA DE COOPERAÇÃO (ABC). Coordenação-Geral de Cooperação Humanitária. 2019. Disponível em: $<$ http://www.abc.gov.br/Projetos/CooperacaoHumanitaria $>$. Acesso em: 10/12/2020.

AGÊNCIA BRASILEIRA DE COOPERAÇÃO (ABC). Pesquisa de Projetos. 2019. Disponível em:< http://www.abc.gov.br/Projetos/pesquisa > . Acesso em: 10/12/2020.

AMORIM, Celso. Teerã, Ramalá e Doha: memórias da política externa ativa e altiva. Benvirá, 2015 .

BIBLIASPA. Integração ASPA. Disponível em: <https://bibliaspa.org/mecanismo-aspa/> . Acesso em: 10/12/2020.

BRENER, Jayme. Trinta anos de não alinhados. Lua Nova: revista de cultura e política, v. 3, n. 3, p. $78-81,1987$.

BRUN, Élodie. La diplomacia brasileña hacia el Medio Oriente: una estrategia oscilante. Araucaria. Revista Iberoamericana de Filosofía, Política y Humanidades, v. 14, n. 28, p. 73-90, 2012. Disponível em: <https://www.redalyc.org/pdf/282/28224469005.pdf > . Acesso em: 10/12/2020.

CAMPOS, P. H. P.. A trajetória da Mendes Júnior: um caso emblemático de uma das empreiteiras da ditadura. In: XII Congresso Brasileiro de História Econômica \& 13a Conferência Internacional de História de Empresas, 2017, Niterói. Anais do XII Congresso Brasileiro de História Econômica \& 13a Conferência Internacional de História de Empresas. Niterói: ABPHE, 2017. v. 12. p. 1-15. Disponível em:< https://bit.ly/2XHIUtq >. Acesso em: 10/12/2020.

CEPAL. Comissão Econômica para a América Latina e o Caribe; Publicações. 2020. Disponível em:<https://www.cepal.org/pt-br/publications $>$. Acesso em: 10/12/2020.

CHADE, Jamil. Alinhado a Trump, Brasil sediará reunião dos EUA sobre paz no Oriente Médio. 2019. Disponível em: <https://noticias.uol.com.br/colunas/jamilchade/2019/12/11/brasil-afaga-trump-e-sediara-reuniao-dos-eua-sobre-paz-no-orientemedio.htm >. Acesso em: 10/12/2020. 
CORNETET, João Marcelo Conte. A política externa de Dilma Rousseff: contenção na continuidade. Conjuntura Austral, v. 5, n. 24, p. 111-150, 2014.

ICARABE. Livro destaca papel de D. Pedro II na imigração árabe. Instituto da Cultura Árabe. Disponível em: <https://icarabe.org/literatura/livro-destaca-papel-de-d-pedro-ii-naimigracao-arabe $>$. Acesso em: 10/12/2020.

ÍNDIA. History and Evolution of Non-Aligned Movement. Disponível em: $<$ http://mea.gov.in/in-focusarticle.htm?20349/History+and+Evolution+of+NonAligned+Movement $>$ Acesso em: 10/12/2020.

ITAMARATY. III Cúpula América do Sul-Países Árabes (ASPA) - Lima, Peru, 2 de outubro de 2012. Disponível em: <https://www.gov.br/mre/pt-br/canais atendimento/imprensa/notas-aimprensa/iii-cupula-america-do-sul-paises-arabes-aspa-lima-peru-2-de-outubro-de-2012>. Acesso em: Acesso em: 10/12/2020.

KALOUT, Hussein; DEGAUT, Marcos. Brasil, um país em busca de uma grande estratégia. Relatório de Conjuntura, v. 1, 2017.

KOCHER, Bernardo. De Bandung A Bagdá: Cinquenta Anos De História E Economia Política Do Terceiro Mundo. Anais Eletrônicos do XI Encontro Regional de História. Rio de Janeiro, ANPUH-RJ, p. 1967-1976, 2004.

LEITE, Patrícia Soares (2011). O Brasil e a Cooperação Sul-Sul em três momentos de Política Externa: os Governos Jânio Quadros/João Goulart, Ernesto Geisel e Luiz Inácio Lula da Silva. Brasília, FUNAG.

MENEM, Issam Rabih. Crise Dos Cargueiros Iranianos e o Direito Marítimo. Orbis Latina, v. 10, n. 1, p. 47-54, 2020. Disponível em: <https://revistas.unila.edu.br/orbis/article/view/1844>. Acesso em: 10/12/2020.

MENEM, Issam Rabih. O Petróleo e o Material Bélico Nas Relações Brasil-Iraque (19701989). Revista de Geopolítica, v. 10, n. 2, p. 48-60, 2019. Disponível em: $<$ http://www.revistageopolitica.com.br/index.php/revistageopolitica/article/view/263>. Acesso em: $10 / 12 / 2020$.

NASSER, Filipe. Pax Brasiliensis: Projeção de poder e solidariedade na estratégia diplomática de participação brasileira em Operações de paz da Organização das Nações Unidas. In: KENKEL, Kai Michael; MORAES, Rodrigo Fracalossi de. O Brasil e as Operações de Paz em um mundo globalizado - Entre a tradição e a inovação. Brasília: IPEA, p. 213-242, 2012.

PEREIRA, Analúcia D.; MEDEIROS, Klei. O Prelúdio da Cooperação Sul-Sul: da Conferência de Bandung à Conferência de Buenos Aires (1955-1978). I Seminário Internacional de Ciência Política. Universidade Federal do Rio Grande do Sul. Porto Alegre, Set, 2015.

PREISS, J. L. S. A Presença De Produtos Da Indústria Bélica Do Brasil E Da Argentina Na Guerra Irã-Iraque (1980-1988). RICRI, v. 2, p. 1-18, 2015.

SCHUTTE, Giorgio Romano; DA FONSECA, Bruno Castro Dias; CARNEIRO, Gabriel Santos. Jogo de Dois Níveis Voltado ao Eleitorado: Uma Análise da Política Externa Bolsonarista. Conjuntura Global, $\quad$ v. $\quad 8, \quad$ n. $\quad 2, \quad 2019 . \quad$ Disponível $\quad$ em: <https://revistas.ufpr.br/conjgloblal/article/view/69854/39896 > . Acesso em: 10/12/2020.

SHQAIR, Qais Marouf Kheiro. Embaixador da Liga dos Estados Árabes para a América do Sul. Entrevista concedida a Issam Rabih Menem. Brasília. 2019. 
TRUZZI, Oswaldo. Presença árabe na América do Sul. História Unisinos, v. 11, n. 3, p. 359-366, 2007.

VAGNI, Juan José. La cumbre América del Sur-Países Árabes (ASPA): Balances de un acercamiento estratégico. Revista de Estudios Internacionales Mediterráneos, n. 8, 2009.

WOLKMER, Antônio Carlos. O terceiro mundo e a nova ordem internacional. Editora Ática, 1989. 